TẠP CHÍ KHOA HỌC ĐẠI HỌC TÂN TRÀO

ISSN: $2354-1431$

http://tckh.daihoctantrao.edu.vn/

\title{
Ảnh hưởng của văn hóa Kinh, Hán tới thi pháp lời thơ nghệ thuật của dân ca trữ tình sinh hoạt Tày
}

\author{
Hà Xuân Hương ${ }^{a^{*}}$ \\ ${ }^{a}$ Truờng Đại học Khoa học- Đại học Thái Nguyên \\ *Email: haxuanhuong_dhkh@yahoo.com.vn
}

\section{Thông tin bài viết}

Ngày nhận bài:

$19 / 5 / 2018$

Ngày duyệt đăng:

$10 / 9 / 2018$

Tù̀ khoá:

Anh huởng, ngôn ngũ, văn hóa, dân ca trũu tình sinh hoạt, ngườ Kinh, người Hán, người Tày.

\section{Tóm tắt}

Do quá trình giao lưu văn hóa Kinh, Hán, Tày, văn hóa Kinh, Hán có tác động lớn tới thi pháp lời thơ nghệ thuật của dân ca trữ tình sinh hoạt Tày trên ba phương diện: Ngôn ngữ, điển tích, thể thơ. Đó là sự đan xen của ngôn ngữ Tày với ngôn ngữ Việt, phần nhiều là từ Hán - Việt trong lời thơ nghệ thuật. Từ đó dẫn đến việc sử dụng nhiều các điển tích có nguồn gốc Hán tộc và Việt tộc. Thể thơ chủ đạo trong dân ca trữ tình sinh hoạt Tày là thể thất ngôn với hai kiểu là thất thất lưu thủy và thất ngôn tứ tuyệt. Những đặc điểm này khiến cho dân ca trữ tình sinh hoạt Tày mang tính bác học, trí tuệ, gần gũi hơn với văn học thành văn của người Kinh, Hán. Tuy thế, trong quá trình tiếp thu, người Tày đã biến cải phần nào những yếu tố ảnh hưởng cho phù hợp với đặc điểm tâm lí tộc người. Điều đó khiến cho phần lời của dân ca trữ tình sinh hoạt Tày mang vẻ đẹp vừa công phu, kiểu cách, lại vừa tự nhiên, bình dị.

\section{1. Đặt vấn đề}

Trải quan hàng ngàn năm lịch sử, do sự hòa hợp dân tộc diễn ra trên những sự kiện có thuộc tính xã hội và hiện tượng sinh học trên con người cụ thể, dân tộc Tày ở Việt Nam hiện nay là sự hợp thành của bốn thành phần: bộ phận người Tày bản địa, bộ phận người Tày gốc Kinh, bộ phận Tày gốc Nùng, bộ phận người Tày thuộc các nhóm đồng tộc đến từ Trung Quốc. Điều đó dẫn tới sự giao lưu, tiếp biến văn hóa giữa người Tày và người Kinh, người Hán thông qua các mối quan hệ trực tiếp hoặc gián tiếp. Văn hóa Kinh, Hán tác động đến văn hóa Tày trên nhiều phương diện. Ở lĩnh vực văn học dân gian, sự ảnh hưởng đó thể hiện rất rõ ở thi pháp lời thơ lời thơ nghệ thuật của dân ca trữ tình sinh hoạt Tày.

\section{Phương pháp nghiên cứu}

Nghiên cứu vấn đề này, chúng tôi sử dụng ba phương pháp chính: Phương pháp thống kê, phương pháp tiếp cận từ góc độ thi pháp học, phương pháp liên ngành.
Phương pháp thống kê được sử dụng để thống kê các số liệu cụ thể liên quan đến ngôn ngữ, điển tích, thể thơ. Các kết quả thống kê là căn cứ để chúng tôi đưa ra các suy luận, nhận định khoa học. Đồng thời, việc sử dụng các phương pháp này cũng giúp tăng thêm sức thuyết phục, độ chính xác, tin cậy cho những nhận định khoa học của chúng tôi. Trong khi đó, phương pháp tiếp cận từ góc độ thi pháp học là không thể thiếu để chúng tôi đi sâu khám phá các đặc điểm thi pháp của lời thơ nghệ thuật của dân ca trữ tình sinh hoạt Tày. Về phương pháp liên ngành, chúng tôi sử dụng các kiến thức về văn hóa, văn học, ngôn ngữ, lịch sử để lí giải cho sự ảnh hưởng của văn hóa Kinh, Hán tới các phương diện nghệ thuật của dân ca trữ tình sinh hoạt Tày.

\section{Kết quả nghiên cứu}

3.1. Các đặc điểm thi pháp lò̀i tho nghệ thuật trong dân ca trũ tình sinh họ̣t Tày chịu ảnh hưởng của văn hóa Kinh, Hán

\subsubsection{Ngôn ngũ}


Sự ảnh hưởng về mặt ngôn ngữ tới dân ca trữ tình sinh hoạt Tày không chỉ thể hiện ở việc người Tày sử dụng chữ Nôm Tày để sáng tác dân ca - một loại văn tự tượng hình được kế tục và phát triển dựa trên chữ Hán mà còn thể hiện ở sự đan xen về mặt ngôn ngũ trong lời thơ nghệ thuật của dân ca trữ tình sinh hoạt Tày. Điều dễ nhận thấy là lời thơ có sự đan xen của tiếng Tày, tiếng Việt với hình thức ngữ âm cổ và từ Hán Việt.

Cụ thể, trong dân ca trữ tình sinh hoạt Tày có sự xuất hiện của tiếng Việt với hình thức ngữ âm cổ như: mủa xuân - mùa xuân, kiết bạn - kết bạn, vội vạngvội vàng, hại - hãy, én - én, tiểng - tiếng... Đặc biệt, không thể không kể đến sự xuất hiện của các từ Hán Việt. Trong khuôn khổ một bài báo, chúng tôi chỉ xin lấy hai ví dụ nhỏ về sự đan xen ngôn ngữ như sau: Trong 10 lời dân ca đầu tiên được công bố trong cuốn Rọi (Vốn cổ văn học dân tộc Tày - Nùng), chúng tôi thấy có 11 đơn vị từ tiếng Việt cổ và 36 đơn vị từ Hán Việt. Tương tự, khi xem xét 10 lời đầu trong cuốn Lươn Tày: Lươn Tày Lạng Sơn, lượn slương, chúng tôi thấy có 10 đơn vị từ tiếng Việt cổ và 39 đơn vị từ Hán - Việt, kiểu như:

\section{Mở bài khai khẩu ước chào xuân}

Tiểng cạ rườn rầu mì ái $a ̂ n[6$, tr. 43$]$

(Mở bài đầu tiên lời chào xuân/ Tiếng rằng nhà mình có ái ân) [6, tr. 189]

\section{Chàng hoa phong cảnh tứ thì ban}

Bách thảo hoa khai pây rạo ngàn

Nguói bạn thần thông mà cạ nẩy

Thiết tình chi tử vọng cằm khan.[6, tr. 43 - 44]

(Chàng hoa phong cảnh bốn mùa tươi/Bách thảo nở hoa, đi dạo chơi/Gửi bạn thần thông nhắn bạn tới/Tiếc gì công sức lượn vài khan) [6, tr. 189 - 190]

Từ hai ví dụ này, rà soát lại đối với các lời dân ca trong các công trình sưu tầm, công bố tư liệu dân ca trữ tình sinh hoạt Tày, chúng tôi thấy trong ngôn ngũ đan xen, phần lớn là từ Hán - Việt. Hơn thế, chúng là những từ khá gần gũi với tiếng Việt hiện đại về phương diện ngữ âm và ngữ nghĩa, chỉ khác về cách ghép từ do có sự chi phối của tư duy ngôn ngữ dân tộc Tày. Sự gần gũi đó có thể được lí giải như sau: Về mặt lí thuyết, dân ca trữ tình sinh hoạt Tày ra đời rất sớm. Song, việc ghi chép lại dân ca Tày mới chỉ diễn ra sớm nhất vào những năm ba mươi của thế kỉ XX với
Nguyễn Văn Huyên. Trong công trình nổi tiếng của mình, Nguyễn Văn Huyên lại dịch thơ ca dân gian Tày ra tiếng Pháp chứ không dịch ra tiếng Việt. Những bản dịch dân ca Tày ra tiếng Việt sớm nhất ở miền Bắc là vào những năm sáu mươi. Công trình công bố tư liệu dân ca trữ tình sinh hoạt Tày theo hình thức song ngữ Tày - Việt sớm nhất là Rọi (Vốn cổ văn học dân tộc Tày - Nùng) của nhóm tác giả Trương Lạc Dương, Nông Đình Tuấn, Trần Vĩnh, Võ Quang Nhơn vào năm 1970. Ngôn ngữ và văn hóa luôn biến đổi. Cho nên, những văn bản dân ca hiện chúng ta đang quan sát có lịch sử vài trăm năm trước Cách mạng tháng Tám năm 1945. Sự gần gũi về phương diện ngữ âm của các từ Hán - Việt trong dân ca trữ tình sinh hoạt Tày là có thể hiểu được.

Do sử dụng nhiều từ Hán - Việt trong lời thơ nghệ thuật nên ngôn ngữ trong dân ca trữ tình sinh hoạt Tày dễ gây ấn tượng là tính trang trọng, kiểu cách. Có thể lấy ví dụ rất rõ ràng trong ngôn ngữ xây dựng nhân vật trữ tình của dân ca tình yêu. Trên cơ sở tiếp thu nguyên vẹn và tiếp thu có biến cải ngôn ngữ của người Việt, người Tày đã sáng tạo ra những cách nói ước lệ nhằm tôn tinh, ca ngợi tuyệt đối người yêu của mình. Mọi thứ thuộc về tình yêu đều được đặt cao hơn hiện thực cuộc sống nhiều lần, trở nên trang trọng một cách quý tộc nhờ vào các từ ngữ Hán - Việt được sử dụng. Điều đó thể hiện qua cách xưng hô với người mình yêu. Chàng trai Tày được gọi là: sĩ tử, nho sĩ, slấy, quân tử, quan, pỉ quan (quan anh)... cô gái Tày được gọi là: nàng, dương nga, kình châm (đều với nghĩa là những cô tiên, em đẹp)... Nơi ở của các nàng có phòng hương (phòng xông hương của con gái quý tộc), phòng loan...các chàng trai có ngự đường trần (nằm giường bạc). Nơi hẹn hò của họ là chốn Đào Nguyên, hồ Hải Lăng, hồ Tây Hải, chốn Bồng Lai, chốn Đông Quân...

\section{Nhẳm lì̀a lồng lọt chổn Đào Nguyên}

Nho sinh thiểu nụ bạn duyên hiền

Giờ này sloong rà cụng khéc loọc

Noọng hội mà rưòn dá phụ duyên. [6, tr. 310]

(Chèo thuyền xuống tới chố Đào Nguyên/Nho sinh tố nũ đôi bạn hiền/Giờ này hai ta thành khác lạ/Em hỡi về nhà chó phụ duyên). [6, tr. 431]

Vì đặc điểm sử dụng ngôn ngữ như trên, đọc nhiều lời dân ca tình yêu của người Tày, thấy khá 
gần gũi với văn chương trung đại của người Việt. Xin nêu ví dụ:

Thảo mộc cắt đảng hua tổng canh

Chức Nụ văn phòng thiếu nụ anh

Duyên cần mì rườn cầu chắc đuổi

Duyên cần mì mả cầu chắc đành. [6, tr. 313]

(Cỏ cây giá lạnh đầu trống canh/Chức Nũ trong phòng giũ phận mình/Duyên em thành ra ai biết đượ/Sợ em có chồng lại dối anh) [6, tr. 434]

aNhư thế, ngôn ngữ Việt đã có sự thâm nhập sâu rộng vào ngôn từ nghệ thuật của dân ca trữ tình sinh hoạt Thái. Tất nhiên, nói như thế bao hàm cả sự ảnh hưởng của ngôn ngữ Hán thông qua bộ phận từ Hán Việt. Xét về dạng thức thì ngôn ngữ Việt ảnh hưởng trực tiếp, ngôn ngữ Hán ảnh hưởng gián tiếp thông qua ngôn ngữ Việt.

\subsection{2. Điển tich}

Đặc điểm đan xen về ngôn ngữ dẫn tới một đặc điểm nổi bật khác của dân ca trữ tình sinh hoạt Tày là việc ngôn từ nghệ thuật giàu điển tích. Tìm hiểu việc sử dụng điển tích trong dân ca trữ tình sinh hoạt của người Tày, chúng tôi nhận thấy có ba điểm nổi bật.

Thứ nhất, về nguồn gốc của điển tích. Điển tích trong dân ca Tày khá đa dạng. Các bài ca tình yêu của người Tày thường lấy điển tích từ các truyện cổ hoặc trong lịch sử như Lương Quân - Bjoóc Lả, Tư Mã Văn Quân, Ngưu Lang Chức Nữ, Lương Sơn Bá Chúc Anh Đài, Hà Bá Long Vương với Thủy Tinh, Tư Mã Tương Như - Trác Văn Quân, Lưu Đài Hán Xuân, Nam Kim - Thị Đan... Phân loại các điển tích, chúng tôi thấy chúng có thể xuất phát từ ba nguồn gốc:

- Vay mượn của Trung Quốc: Lương Sơn Bá Chúc Anh Đài, Trương Lương, Tiêu Hà, Hàn Tín, Chiêu Quân, vua Trụ - Đát Kỷ, Thần Nông, Hữu Sào, chốn Đào Tiên, Đông Quân, vua Thuẫn, Thục đế Hằng Nga...

- Vay mượn trong kho văn liệu của văn học người Kinh: Thánh Gióng, vua Thái Tông, Phạm Tải - Ngọc Hoa, trầu cau...

- Nguồn gốc bản tộc: Lương Quân - Bjoóc Lả, Lưu Đài Hán Xuân, Nam Kim - Thị Đan, Huyền Linh, Huyền Quang...

Việc sử dụng hai nhóm điển tích có nguồn gốc Kinh tộc và Hán tộc là kết quả của sự giao lưu và tiếp biến văn hóa Tày, Kinh, Hán. Tuy có nguồn gốc vay mượn nhưng khi đi vào dân ca trữ tình sinh hoạt Tày, các tích truyện xưa cũ, những nhân danh, địa danh... đã ít nhiều được vận dụng biến đổi cho phù hợp với đặc điểm của dân tộc, vùng miền, khiến cho nó mang đậm màu sắc dân tộc. Điển tích đã thoát thai đời sống cũ trong các sự kiện của người Kinh và Trung Quốc. Chẳng hạn, Chiêu Quân là một trong tứ đại mỹ nhân trong lịch sử Trung Quốc. Nhắc đến Chiêu Quân, ai cũng nghĩ ngay đến tích Chiêu Quân cống Hồ. Thế nhưng, tác giả dân gian khi sáng tác dân ca đã khéo léo Tày hóa tích này bằng việc biến Chiêu Quân thành người con gái nước Việt bị triều đình đem đi cống giặc phương Bắc. Nàng bị đem đi triều cống trong tâm trạng nhớ quê đau lòng, công cha nghĩa mẹ sinh thành chưa báo đáp. Hàng loạt các chi tiết cho thấy Chiêu Quân triều cống là sản phẩm của Việt Nam chứ không phải Trung Quốc cổ: Chiêu Quân ăn trầu (liên quan đến ý nghĩa sự tích Trầu cau của Việt Nam), Chiêu Quân đi thuyền (ở Trung Quốc, từ kinh đô nhà Hán đến Hung Nô không có đường thủy), Chiêu Quân trở về An Nam được phong quan cai bảy huyện... Hơn thế, tích Chiêu Quân còn được Tày hóa cao độ khi cho rằng vua Hán là của Việt Nam, vua Tần là vua Hung Nô:

\section{Chiêu Quân pây sử nuớc Hồ vuoong}

Vua Hản nhằng dú chưc nặm muờng

Slắng các quan triều tằng chu tuởng

Vua Hản đảy nhin toong xam thuoong. [6, tr. 353]

(Chiêu Quân đi sú nước Hồ Vuơng/Vua Hán ở lại giũ bản muờng/Dặn cả quan triều và các tuớng/Vua Hán nghe tiếng lòng xót thuoong) [6, tr. 475]

Hoặc, bài lượn Lương Sơn Bá - Chúc Anh Đài cũng vay mượn một tích truyện của Trung Quốc. Thế nhưng, nếu nguyên bản ở Trung Quốc, kết thúc câu chuyện, đôi trai gái biến thành uyên ương hồ điệp, mãi mãi bên nhau thì ở bài lượn của người Tày ở Lạng Sơn, Anh Đài tự vẫn ở trên rừng, biến thành chim khảm khắc. Đây là loài chim thường được nhắc tới trong dân ca tình yêu của người Tày. Khảm khắc là loài chim nhỏ, kêu về đêm từ cuối xuân đến thu. Tiếng chim thê lương trong đêm đen, da diết, não nề vọng lại từ ngọn đồi xa hay rừng già khiến lòng người sầu thảm. Người Tày thường cho rằng con chim vì mất bạn tình nên trở thành lẻ loi mà than thân, chim khảm khắc là biểu tượng bộc bạch tâm tư, nỗi sầu bi của con 
người.Việc để Anh Đài hóa thành chim khảm khắc là minh chứng rõ ràng cho sự đồng hóa của các điển tích Trung Quốc vào dân ca trữ tình sinh hoạt Tày.

Thứ hai, cách sử dụng điển tích của người Tày có phần đặc biệt. Nên cạnh cách thông thường là điển tích có thể chỉ được điểm thoáng qua trong bài hát, điển tích trong dân ca tình yêu của người Tày còn được hát thành một bài hát dài. Điều này đặc biệt phổ biến trong các chương lượn sử. Các tích truyện như Chiêu Quân, Đài Linh, Bjoóc Lồm, Lưu Nguyễn sử kinh, Nam Kim - Thị Đan... được hát nhằm khéo gợi đối phương noi theo. Cả diễn xướng lượn cọi và lượn slương đều có thể có lươn sử. Một cuộc hát mà có phần lượn sử tức tình duyên đã đạt đến độ chín.

Thứ ba, sự xuất hiện của điển tích trong dân ca trữ tình sinh hoạt Tày là khá dày đặc. Theo kết quả khảo sát của chúng tôi, từ 1464 lời dân ca trữ tình sinh hoạt thống kê từ các công trình sưu tầm, biên dịch:

- Tổng tập văn học dân gian các dân tộc thiểu số Việt Nam, tập 18 - Dân ca [9].

- Tổng tập văn học dân gian các dân tộc thiểu số Việt Nam, tập 19 - Dân ca [10].

- Chồm bjoóc mạ [3].

- Lượn Tày: Lượn Tày Lạng Sơn, lượn slương [6].

- Phong slư [2].

- Thành ngữ, tục ngũ̃, ca dao dân tộc Tày [1].

Chúng tôi nhận thấy điển tích xuất hiện 130 lần, chiếm tỉ lệ $13 \%$. Đặc biệt, người Tày có các chương lượn sử. Ở đó, cả một chương dài chỉ hát về một tích truyện trong lịch sử hoặc truyền thuyết, cổ tích. Đặc điểm này liên quan đến phong cách văn chương của mỗi dân tộc. Lực lượng sáng tác dân ca Tày chủ yếu là những trí thức dân tộc, những nghệ nhân có tài nên ưa dùng các điển tích như phong cách văn chương bác học. Điều đó khiến cho dân ca Tày thiên về chất trí tuệ.

\subsubsection{Thể tho}

Dân ca trữ tình sinh hoạt Tày sử dụng các thể tự do, thể ngũ ngôn, thể thất ngôn. Trong đó, thể thơ chính là thể thất ngôn. Người Tày dùng cả thất ngôn tứ tuyệt, thất ngôn trường thiên và song thất. Với việc sử dụng thể thơ này, dân ca trữ tình sinh hoạt Tày tiến dần tới sự chuyên nghiệp hóa.

Chúng tôi khảo sát từ 1464 lời dân ca thống kê tù̀ các công trình nêu ở phần trên thì có đến 1275 lời (chiếm $87 \%$ ) được làm theo thể thơ thất ngôn. Các thể khác chiếm tỉ lệ ít: Thể tự do chiếm 12.8\%, thể ngũ ngôn chiếm $0.2 \%$.

Người Tày có luợn cọi, lượn then, phong slu, luợn slương... đều là những loại hình dân ca giao duyên và được sáng tác theo thể thất ngôn. Trong đó, luợn cọi, luợn then, phong slu... được sáng tác theo thể thất ngôn trường thiên, hay còn gọi là thất thất lưu thủy. Đây là thể thơ sử dụng vần chân (chữ cuối của câu trên vần với chữ lưng của câu dưới, thường là chữ thứ năm). Cách gieo vần này tương tự cách gieo vần trong câu song thất thuộc thể thơ song thất lục bát của người Việt. Người Việt gieo vần yêu vận ở hai câu thất của bài ca dao làm theo thể song thất lục bát:

Nước hồ Tây vì̀a trong vìa mát

Đuờng chọ Bười lắm cát dễ đi

Cô kia bóng bảy làm chi

Để cho anh ấy đi đi về về. [8, tr. 180]

Trong thể thất ngôn trường thiên của dân ca trữ tình sinh hoạt Tày, từ hai câu đầu gieo yêu vận, các câu thơ tiếp theo cứ theo quy luật này mà lặp lại. Từ đó, bài dân ca có thể dễ dàng kéo dài.

\section{Buơn chiêng ngòi hăn bjoóc một than}

Mọi thức bjoóc phung ban tềnh cáng

Ong điệp bên vội váng tím xa

Một mèng bên pây mà tím nhị

Nhu là than noọng nhỉ bấu hăn ...[7, tr. 206]

(Tháng giêng trồng hoa nở là than/Mọi thư hoa ban nở trên cành/Ong bướm bay rộn ràng tìm thăm/Kiến ong cũng vội vàng tìm nhị/Nhu đang tìm bạn nghĩa mất đâu...) [7, tr. 522]

Tuy thế, cần lưu ý lí do chính để các bài luợn cọi, phong slu, lươn sủ... có dung lượng lớn không hoàn toàn do việc sử dụng thể thất thất lưu thủy. Trên thực tế, các thể lục bát, song thất lục bát... phổ biến trong dân ca của người Kinh cũng có thể được sử dụng để gia tăng dung lượng của tác phẩm. Thế nhưng, ở dân ca của người Kinh chúng ta ít gặp trường hợp bài dân ca dài quá 20 câu. Sự khác nhau giữa độ dài của lượn cọi, luợn then... của người Tày so với dân ca của người Kinh lúc này không phụ thuộc vào thể thơ. Cụ thể, độ ngắn của dân ca của người Kinh phụ thuộc đặc điểm của lối hát đối đáp. Đối đáp là một hình thức tỏ tình của nam nữ thanh người Kinh. Đặc trưng của lối hát đối đáp là ngắn gọn. Tài năng của người đối đáp không phụ thuộc độ dài ngắn mà phụ thuộc vào khả 
năng ứng tác nhanh, nội dung sâu sắc. Trong khi đó, ở người Tày, ngoài hình thức đối đáp nhằm thể hiện tài năng của người hát, dân ca trữ tình sinh hoạt Tày còn có một bộ phận không liên quan đến tính chất thi tài giữa các bên hát. Chẳng hạn, luợn sử liên quan tới việc mượn các tích truyện xưa cũ trong lịch sử, truyền thuyết... để nhắc nhở bạn tình noi theo, hoặc phong slu liên quan tới sự bộc lộ tình cảm buồn nhớ triền miên, lươn cọi tuy là đối đáp nhưng không đặt mục đích thi tài ứng tác mà đề cao tính trình tự của nội dung hát cùng tài ghi nhớ của các chàng trai. Chính vì thế, các bài hát luợn sủ, phong slu, lươn cọi thường khá dài.

Như vậy, độ dài của bài dân ca trữ tình sinh hoạt vì lí do sử dụng thể thất ngôn trường thiên mà chúng tôi nghiên cứu ở đây chỉ có ý nghĩa phân biệt với độ ngắn của thể bài dân ca trữ tình sinh hoạt do được làm theo thể thất ngôn tứ tuyệt mà chúng tôi sẽ phân tích ở sau.

Vì được làm theo thể thất ngôn trường thiên nên nhiều bài dân ca trữ tình sinh hoạt của người Tày có dung lượng khá lớn. Chẳng hạn như cung lượn 12 tháng (slip nhí bươn) dài 249 câu. Các bài lượn còn có thể dài hơn thế, tùy thuộc vào nội dung và tài nghệ của những người tham gia vào cuộc lượn.

Như trên đã trình bày, thể thất ngôn trường thiên sử dụng yêu vận, chữ cuối cùng của câu trước bắt vần với chữ thứ năm của câu sau. Nếu chữ cuối câu trước là vần bằng thì chữ thứ năm câu sau cũng vần bằng. Ngược lại, nếu chữ cuối câu trước là vần trắc thì chữ thứ năm câu sau cũng là vần trắc. Cả bài dân ca dung nạp cả vần bằng, trắc trong gieo vần tạo nhịp, khiến cho bài dân ca uyển chuyển, linh hoạt. Điều này rất có ý nghĩa đối với việc thể hiện tâm hồn, tình cảm của con người: khi êm đềm, lắng đọng, khi mạnh mẽ, mãnh liệt. Vì ưu thế đó, thể thất thất lưu thủy được sử dụng trong sáng tác luợn cọi, phong slu, luợn then... bởi so với luợn sluơng, các tiểu loại này rộng rãi hơn về nội dung bài hát.

Trong luợn cọi, thỉnh thoảng có những bài mà có câu chỉ gồm 5 tiếng, kiểu biến thể. Lúc này, việc gieo vần cuối của câu trước sẽ rơi vào bất kì tiếng nào của câu tiếp. Như thế, vẫn là gieo yêu vận nhưng chữ lưng không cố định là tiếng thứ mấy, chỉ trừ tiếng cuối cùng. Chẳng hạn:

\section{Hua cẳm moóc tỏa bản}

Cần tồn mì lục nhạn mà nòn... [7, tr. 14]

(Đầu hôm mây che bản/Đồn rằng có con nhạn qua đêm...) [7, tr. 322]
Kiểu gieo yêu vận như trên còn được áp dụng trong thể song thất của dân ca trữ tình sinh hoạt Tày, tương tự như thể song thất trong dân ca của người Kinh. Bên cạnh đó, thể tự do cũng dùng lối gieo vần yêu vận. Tuy nhiên, các thể song thất và tự do đều chiếm tỉ lệ rất nhỏ trong dân ca trữ tình sinh hoạt Tày.

Khác với luợn cọi, lươn then, phong slu là loại dân ca sử dụng vần lưng để kéo dài khổ thơ, luợn slương chỉ dùng loại thất ngôn tứ tuyệt là chính. Các câu 1, 2 , 4 vần với nhau như lối thơ Đường cổ xưa. Do thể thất ngôn tứ tuyệt có sự quy định rõ ràng về số câu trong một bài nên ở bài dân ca luợn sluoongluôn chỉ gồm 4 câu, không có sự kéo dài tùy hứng như luợn cọi, phong sluw...

\section{Cáy khăn liểu oóc tiểng cáy khăn \\ Lo tềnh nuxa phạ oóc rụng vằn}

Bạn hơi nhằng thuoong rà hại lỉn

Xiết hại sloong rà thuoong chứ căn. [6, tr. 303]

(Gà gáy đi dạo gà gáy ran/Sọ tròi cao rạng sáng mênh mang/Bạn có lòng thương thời chơi đã/Kẻo nũa hai ta lai nhớ than) [6, tr. 435]

Việc sử dụng thể thất ngôn này có liên quan đến đội ngũ sáng tác dân ca Tày, bao gồm các nghệ nhân có tài, các trí thức bình dân của dân tộc. Ở từng vùng, nổi lên vai trò của các nghệ nhân dân gian nổi tiếng. Chẳng hạn, ở thôn Đồng Uẩn, xã Phúc Chu, huyện Định Hóa, tỉnh Thái Nguyên có nghệ nhân Lưu Xuân Lai, ở xã Hưng Khánh, huyện Trấn Yên, tỉnh Yên Bái có nghệ nhân Hoàng Kế Quang, ở xã Tân An, huyện Chiêm Hóa, tỉnh Tuyên Quang có nghệ nhân Hà Phan, Hà Thuấn...Họ là những người biết nhiều, giỏi sử dụng và sáng tác dân ca. Họ có vai trò lớn trong việc trau dồi vần điệu dân ca, tạo nên thể thơ với quy cách vần điệu ngày càng ổn định.

\subsection{Nguyên nhân dẫn đến sự ảnh hưởng của văn hóa Kinh, Hán tới thi pháp lò̀i tho nghệ thuật trong dân ca trũ tình sinh hoạt Tày}

Sự tác động của văn hóa Kinh, Hán đến nhiều đặc điểm thi pháp lời thơ nghệ thuật của dân ca trữ tình sinh hoạt của người Tày như trên xuất phát từ quá trình giao lưu, tiếp biến văn hóa Kinh, Hán, Tày, xảy ra bởi hai nguyên nhân: nguồn gốc dân tộc và địa bàn cư trú.

Thứ nhất, về nguồn gốc dân tộc: Người Kinh lên sinh sống ở vùng người Tày, lâu dần bị đồng hóa 
thành người Tày theo lối "Kinh già hóa thổ" (Keo ké piến Tày). Họ bị đồng hóa thành người Tày vì những lí do cụ thể sau:

Đông Bắc là vùng có vị trí chiến lược quan trọng trong việc củng cố an ninh quốc phòng của Việt Nam. Vì thế, các triều đình phong kiến buộc phải chú ý áp đặt sự thống trị của mình lên vùng này. Sau cuộc khởi nghĩa của Nùng Trí Cao, nhà Lý và các triều đại phong kiến kế tiếp đã tổ chức cai trị nhân dân vùng biên giới chặt chẽ hơn bằng cách thực hiện chế độ lưu quan. Các vị quan khi lên cai trị vùng Tày thường đem theo gia quyến, binh lính, phu phen tạp dịch... lên chiêu dân lập ấp và trở thành quý tộc địa phương, cha truyền con nối cai trị từng vùng. Trong quá trình cư trú lâu đời tại địa phương, những người Kinh này dần bị Tày hóa.

Bộ phận người Tày gốc Kinh còn xuất phát từ nguồn binh lính đi dẹp loạn ở miền núi, sau đó ở lại địa phương kết hôn với người miền núi, sinh cơ lập nghiệp tại đây, con cháu nhiều đời bị Tày hóa.

Các cuộc chiến tranh giữa các thế lực phong kiến trong nước nhằm tranh chấp quyền lực cũng có ảnh hưởng nhất đinh tới lịch sử hình thành của dân tộc Tày hiện đại, điển hình là cuộc chiến tranh giữa các tập đoàn Lê - Trịnh và Mạc kéo dài gần suốt thế kỉ XVII. Khi nhà Mạc thất thế ở miền xuôi đã phải chạy lên chiếm đóng Cao Bằng (1595 - 1667). Năm 1667, nhà Mạc diệt vong. Con cháu và dư đảng của nhà Mạc phải sống mai danh ẩn tích, đồng hóa với người Tày, góp phần tạo nên một bộ phận lớn người Tày gốc Kinh ở Cao Bằng, Lạng Sơn.

Ngoài ra, bộ phận người Kinh hóa Tày còn bao gồm các thầy đồ miền xuôi lên miền núi dạy học và nhân dân miền xuôi bị nạn đói kém, loạn lạc, phải chạy lên miền núi, ở lại địa phương, làm ăn lâu đời rồi bị đồng hóa thành người Tày.

Như thế, từ thế kỉ XI trở đi, cùng với việc biên giới Việt Trung được quy định rõ ràng hơn và việc củng cố quyền lực nhà nước phong kiến tập quyền của các triều đại, dân tộc Tày ở vùng Đông Bắc được hình thành nhờ có sự tham góp của bộ phận Kinh hóa Tày.

Bên cạnh đó, văn hóa Hán lại thường ảnh hưởng đến vùng Tày thông qua vai trò của bộ phận người Nùng hóa Tày và bộ phận những người đồng tộc đến từ bên kia biên giới. Đây là những người có cùng nguồn gốc với người Tày Việt Nam, di cư từ vùng nam Choang Quảng Tây (Trung Quốc) đến vùng Đông Bắc Việt Nam. Trong quá trình cộng cư của họ và người Tày đã xảy ra hiện tượng hóa Tày, phổ biến ở các địa phương như Cao Bằng, Lạng Sơn, Bắc Kạn. Trong lịch sử, triều Nguyễn từng có chủ trương đổi người Nùng ở Cao Bằng thành người Thổ, tức Tày bản địa (năm Minh Mệnh thứ 13). Theo đó, những người Choang từ Trung Quốc sang Việt Nam được trên 200 năm, không sống tụ cư, không giữ được bản sắc dân tộc thì gọi là Tày. Khi người Nùng vào Việt Nam đã mang theo những yếu tố văn hóa Hán đã ăn sâu vào máu thịt họ khi còn ở Trung Quốc. Điều đó khiến cho văn hóa Hán ảnh hưởng đến văn hóa Tày trực tiếp qua văn hóa của bộ phận người đến từ Trung Quốc.

Tiếp theo là những ảnh hưởng của văn hóa Hán thông qua người Kinh, biểu hiện bằng việc mở trường lớp học hành, thi cử, truyền bá văn tự, văn hóa Hán ở vùng Tày, góp phần hình thành lớp nhà nho bình dân của dân tộc.

Thứ hai, người Tày có sự tiếp xúc văn hóa với người Kinh và người Hán nhiều là do người Tày chủ yếu sinh sống ở vùng đất giáp ranh Hán - Kinh. Ây là vùng đất bắc Hán, xuôi Kinh. Người Tày có câu: Đoi Keo piạc, đoi Hác mà (Mưa ngâu từ miền Kinh hết, mưa ngâu từ miền Hán về) [5, tr. 251]

Như thế, người Tày chịu ảnh hưởng từ người Kinh thông qua bộ phận người Kinh hóa Tày và; chịu ảnh hưởng của văn hóa Hán gián tiếp thông qua sách vở của người Kinh và trực tiếp thông qua bộ phận người Nùng và những người đồng tộc đến từ Trung Quốc hóa Tày. Đồng thời, sự ảnh hưởng còn có nguyên nhân từ việc người Tày sống cộng cư, cận cư cùng người Kinh, Hán.

\section{Kết luận}

Do những đặc điểm về nguồn gốc dân tộc và địa bàn cư trú, văn hóa Tày đã có sự giao lưu, tiếp biến với văn hóa Kinh, Hán. Sự ảnh hưởng của văn hóa Kinh, Hán tới thi pháp lời thơ nghệ thuật của dân ca trữ tình sinh hoạt Tày là rất rõ, thể hiện ở ba phương diện: Ngôn ngữ, điển tích, thể thơ. Sự ảnh hưởng này khiến cho dân ca trữ tình sinh hoạt Tày mang màu sắc trí tuệ, bác học và dần tiến tới sự chuyên nghiệp hóa, gần với văn học thành văn trong tương quan so với dân ca một số dân tộc ở khu vực miền núi phía Bắc như Thái, Sán Dìu, Dao, H’Mông... Điều đáng quý là trong quá trình tiếp thu, người Tày không chỉ tiếp thu 
nguyên vẹn mà còn tiếp thu có biến cải. Nhờ sự tiếp thu có biến cải mà dân ca trữ tình sinh hoạt Tày mang vẻ đẹp vừa trang trọng, kiểu cách, lại vừa tự nhiên, đậm đà bản sắc dân tộc.

\section{TÀI LIỆU THAM KHẢO}

1. Hoàng Triều Ân (chủ biên) (2014), Thành ngũ Tục ngũu - Ca dao dân tộc Tày, Nxb Văn hóa dân tộc, Hà Nội;

2. Phương Bằng (sưu tầm, phiên âm chữ Nôm và dịch) (2012), Phong slu, Nxb Văn hóa dân tộc, Hà Nội;

3. Hoàng Thị Cấp (sưu tầm và dịch) (1994), Chồm bjoóc mạ, Nxb Văn hóa dân tộc, Hà Nội;

4. Nhiều tác giả (1970), Rọi (Vốn cổ văn học dân tộc Tày - Nùng), Nxb Dân tộc Việt Bắc;

5. Nhiều tác giả (2000), Nguồn gốc lịch sủ tộc người vùng biên giới phía Bắc Việt Nam, Nxb Văn hóa dân tộc, Hà Nội;

6. Hoàng Văn Páo (chủ biên) (2012), Luợn Tày: Lượn Tày Lạng Sơn, luợn sluơng, Nxb Văn hóa dân tộc, Hà Nội;

7.Lục Văn Pảo (sưu tầm, phiên âm và dịch) (1991), Lươn cọi, Nxb Văn hóa dân tộc, Hà Nội;

8. Trung tâm Khoa học Xã hội và Nhân văn quốc gia (2002), Tổng tập Văn hoc dân gian nguời Việt, tập 15 - Ca dao, Nxb Khoa học Xã hội, Hà Nội;

9. Viện Nghiên cứu văn hóa (2007), Tổng tập văn học dân gian các dân tộc thiểu số Việt Nam, tập 18 - Dân $c a$, Nxb Khoa học Xã hội, Hà Nội;

10. Viện Nghiên cứu văn hóa (2007), Tổng tập văn học dân gian các dân tộc, Tập 19-Dân ca, Nxb Khoa học Xã hội, Hà Nội.

\section{Influence of Kinh - Han culture on prosody of lyrical folk songs of Tay people}

Ha Xuan Huong

\section{Article info}

Recieved:

19/5/2018

Accepted:

$10 / 9 / 2018$

Keywords:

Affection, language, culture, romantic folk song, Kinh people, Han people, Tay people.

\begin{abstract}
Due to the process of exchanging Kinh, Han, Tay, Kinh and Han cultures, brought a great impact on the poetic verse of Tay folk songs on three aspects: language, classic reference and prosody. It is a mixture of Tay lyrical languageandVietnamese language, most of it is from Han - Viet in poetry art. This led to the use of many of the Han and ethnic classic references. The main prosodyof lyrical folk songs of Tay people is the loss of two languages is seven and seven - lined stanza. These charcteristics make Tay folk songs more intellectually and closer to the literary writing of the Kinh, Han. However, in the process of acquisition, the Tay people has transformed some of the factors influenced to fit the psychological characteristics of the people. That makes the lyric of the Tay folk songs bringing beauty and sophistication, style, just natural, simple.
\end{abstract}

